\title{
Thermal Characteristics of Helical Coiled Heat Exchanger with Graphene-Deionized Water on Waste Heat Recovery of Combustion Stack Gas
}

\author{
Rithy Kong ${ }^{1}$, Thoranis Deethayat ${ }^{2}$, Attakorn Asanakham ${ }^{2}$, \\ and Tanongkiat Kiatsiriroat ${ }^{2}$
}

\begin{abstract}
${ }^{1}$ Energy Engineering Program, Faculty of Engineering and Graduate School, Chiang Mai University, Chiang Mai 50200, Thailand

${ }^{2}$ Thermal System Research Laboratory, Department of Mechanical Engineering, Faculty of Engineering, Chiang Mai University, Chiang Mai 50200, Thailand

*Corresponding author. E-mail: thoranisdee@gmail.com

https://doi.org/10.12982/CMUJNS.2019.0005
\end{abstract}

Received: March 28, 2018

Revised: July 13, 2018

Accepted: September 11, 2018

\begin{abstract}
Overall heat transfer coefficient of helical coiled heat exchanger with graphenedeionized water (DI-water) for waste heat recovery of combustion stack gas including heat exchanger effectiveness, $\varepsilon$, were experimentally carried out. Various sizes of tube diameter $(1.2-1.5 \mathrm{~cm})$, coil diameter $(19-24.5 \mathrm{~cm})$, and coil pitch $(2.8-6 \mathrm{~cm})$ of helical coils 1-4 including different heat transfer fluids, DI-water and nanofluid (graphene nanoparticles suspended in DI-water) at different particle fractions (0.05, $0.08 \mathrm{wt} . \%)$ had been experimentally studied. The results based on the LMTD-method of countercurrent flows showed that higher graphene fraction resulted in higher values of heat transfer rate, overall heat transfer coefficient and heat exchanger effectiveness. The $\varepsilon^{*}-N T U_{\text {min }}^{*}$ performance curves of the helical coils in series connection for DI-water and nanofluid with $0.05 \mathrm{wt}$ \% graphene were created from Shah and Sekulić model. The calculated results showed that the helical coil 1 gave the best performance. With 5 numbers of this coil and the flow rate of $2 \mathrm{~L} / \mathrm{min}$, the outlet temperature of the nanofluid at $0.05 \mathrm{wt} . \%$ particle fraction was $1.3^{\circ} \mathrm{C}$ over than that of the DI-water. When the coil number was over 7 , the nanofluid gave advantage on the outlet temperature compared with the base fluid only slightly.
\end{abstract}

Keywords: Waste heat recovery, Helical coil, Deionized water, Graphene nanofluid, Heat exchanger effectiveness 


\section{INTRODUCTION}

Waste heat can be classified into high temperature $\left(>650^{\circ} \mathrm{C}\right)$, medium temperature $(230$ $650^{\circ} \mathrm{C}$ ) and low temperature $\left(<230^{\circ} \mathrm{C}\right.$ ) (Zhou et al., 2013). The low temperature waste heat is abundant and it could be found generally in exhaust stacks of small boilers and incinerators. Helical coil is one of the most suitable heat exchangers for waste heat recovery of combustion stack gas due to its simple shape and compactness (Ali, 1994) with low pressure drop in the exhaust gas side. In addition, it provides higher inside heat transfer coefficient than the straight tube because there is a secondary vortex flow generated inside the coil tube which reduces the thermal resistance (Tayde et al., 2014).

There are some studies on the heat transfer of fluid flow in a helical coil with common heat transfer fluids such as water, air, heat transfer oil, and ethylene glycol. There was a report (Janssen and Hoogendoorn, 1978) that showed heat transfer correlation of a fully developed laminar convection heat transfer for water/glycerol mixture flowing inside helical coiled tubes under the condition of constant wall heat flux with various ratios of tube diameter to coil diameter and Reynolds numbers. Dravid et al., (1971) studied the effect of secondary fluid motion on laminar water flow heat transfer in helical coiled tubes. The results showed that the secondary flow increased the heat transfer coefficient and heat transfer rate since the thermal boundary layer became thinner. Schmidt et al., (1967) expressed a correlation of average Nusselt number for determining the heat transfer coefficient of different heat transfer fluids, oil, water and air, in helical coil including the effects of fluid motion, fluid properties and the effect of helical coil dimensions under constant wall heat flux boundary condition. Xin and Ebadian, (1997) also stated a correlation with the effects of Reynolds and Prandtl numbers and coil dimensions such as tube dimeter and coil diameter on local and average convective heat transfer coefficients for air, water, and ethylene glycol flowing inside helical coils under the constant wall heat flux condition. The correlations of Schmidt et al., (1967) and Xin and Ebadian, (1997) could also be applied for deionized water of which the heat transfer results were found to be better than those of normal water (Kong et al., 2018).

In recent years, there have been many research works on the use of nanofluids, nanosized particles (1-100 nm) such as $\mathrm{Al}_{2} \mathrm{O}_{3}, \mathrm{CuO}, \mathrm{SiC}$, etc. suspended in conventional base fluids, to enhance the heat transfer in thermal engineering devices (Mahian et al., 2013). The nanofluid thermal conductivities were higher than those of the base fluids and also the heat transfer rates. Polvongsri and Kiatsiriroat, (2014) used $20 \mathrm{~nm}$ silver particles mixed with water at a concentration of $10,000 \mathrm{ppm}$ in a closed-loop flat plate solar collector. The heat transfer coefficient inside the collector with the nanofluids was nearly double of that with water. The heat transfer enhancements by $\gamma-\mathrm{Al}_{2} \mathrm{O}_{3} /$ water and $\mathrm{TiO}_{2} /$ water were found in the experimental work of Farajollahi et al., (2010). The increase of heat transfer coefficient of ethylene glycol and distilled water mixed with $\mathrm{TiO}_{2}$ nanoparticles in double pipe heat exchanger was figured out by Chandra and Vasudeva, (2014). The increase of heat transfer coefficient was $13.85 \%$ and $10.73 \%$ at particle volume fraction of $0.02 \%$ for with and without helical wire inserts in the heat exchanger, respectively. Kahani et al., (2013) compared the heat transfer performance of $\mathrm{Al}_{2} \mathrm{O}_{3}(35 \mathrm{~nm})$ and $\mathrm{TiO}_{2}(50 \mathrm{~nm})$ particles suspended in distilled water. The results showed that the $\mathrm{Al}_{2} \mathrm{O}_{3}$ particles with smaller size and higher thermal conductivity gave better heat 
transfer performance compared to that of $\mathrm{TiO}_{2}$. In addition, the heat transfer enhancement of $\mathrm{CuO}$ water based nanofluid in laminar flow at various volume fractions $(0.1-0.5 \%)$ inside helical coil heat exchangers was experimentally investigated by Fule et al., (2017). The results showed that the $\mathrm{CuO}$ nanoparticles enhanced the heat transfer coefficient of the base fluid and the enhancements of heat transfer coefficient were found to be $37.3 \%$ and $77.7 \%$ at particle volume fractions of $0.1 \%$ and $0.5 \%$, respectively. Similarly, Bhanvase et al., (2018) experimentally investigated intensified convective heat transfer coefficient of water based PANI (polyaniline) nanofluid at various particle volume fractions $(0.1-0.5 \%)$ in vertical helical coiled heat exchanger. The heat transfer coefficient enhancements of PANI nanofluid were found to be $10.5 \%$ and $70 \%$ at particle volume fractions of $0.1 \%$ and $0.5 \%$, respectively, compared to the base fluid. The heat transfer enhancements of nanofluids containing graphene nanoparticles (GNPs) at different particle specific surface areas of $300,500,700 \mathrm{~m}^{2} / \mathrm{g}$ with particle concentrations less than $0.1 \%$ by weight were found in the experimental work of Mehrali et al., (2014). The latter results indicated higher thermal conductivity of the nanofluid which could reach up to $27.64 \%$ at the concentration of $0.1 \%$ GNPs with a specific surface area of $750 \mathrm{~m}^{2} / \mathrm{g}$.

According to the previous research works, the use of nanoparticles in base fluids could enhance the heat transfer performance of the fluid since the fluid thermal conductivity increases which results in better heat transfer coefficient and more heat transfer rate. However, very few information of heat transfer performance by nanofluids in heat recovery, particularly, heat recovery of combustion stack gas by vertical helical coiled heat exchanger has been reported. In this present study, the graphene nanoparticles at particle fractions of $0.05 \%$ and $0.08 \%$ by weight suspended in distilled water and the fluids were taken as working fluids. The flows were in fully developed laminar regime. The overall heat transfer coefficient and heat transfer rate of working fluids were determined under the countercurrent flow LMTD-method. In addition, the effectiveness of the heat exchangers was determined and the effectiveness curves were created.

\section{MATERIALS AND METHODS}

\section{Heat exchanger effectiveness and outlet temperatures of the working fluids}

Thermal characteristics of helical coil heat exchanger for exchanging heat between hot exhaust gas and working fluid inside the coil could be described by heat exchanger effectiveness, $\varepsilon$, which is

$$
\varepsilon=\frac{\dot{\mathrm{Q}}}{\left(\mathrm{mic}_{\mathrm{p}}\right)_{\min } \cdot\left(\mathrm{T}_{\mathrm{gi}}-\mathrm{T}_{\mathrm{fi}}\right)}
$$

$\left(\dot{\mathrm{m}} \mathrm{c}_{\mathrm{p}}\right)_{\text {min }}$ is the minimum heat capacity between the heat exchanging fluids. $\mathrm{T}_{\mathrm{gi}}$, and $\mathrm{T}_{\mathrm{fi}}$ are the inlet temperatures of the hot gas and the working fluid, respectively. 
$\dot{\mathrm{Q}}$ is the heat rate extracted by the working fluid and it could be calculated as

$$
\dot{\mathrm{Q}}=\left(\dot{m c_{\mathrm{p}}}\right)_{\mathrm{f}}\left(\mathrm{T}_{\mathrm{fo}}-\mathrm{T}_{\mathrm{fi}}\right)=(\mathrm{UA})_{\mathrm{s}} \cdot \Delta \mathrm{T}_{\mathrm{Lm}} \cdot
$$

(UA) $)_{\mathrm{s}}$ is the product of overall heat transfer coefficient and heat transfer area of the heat exchanger and $\Delta \mathrm{T}_{\mathrm{Lm}}$ is log-mean temperature difference between hot gas and working fluid.

To increase heat transfer rate and outlet temperature of the working fluid, the heat exchangers are connected in series as shown in Figure 1.

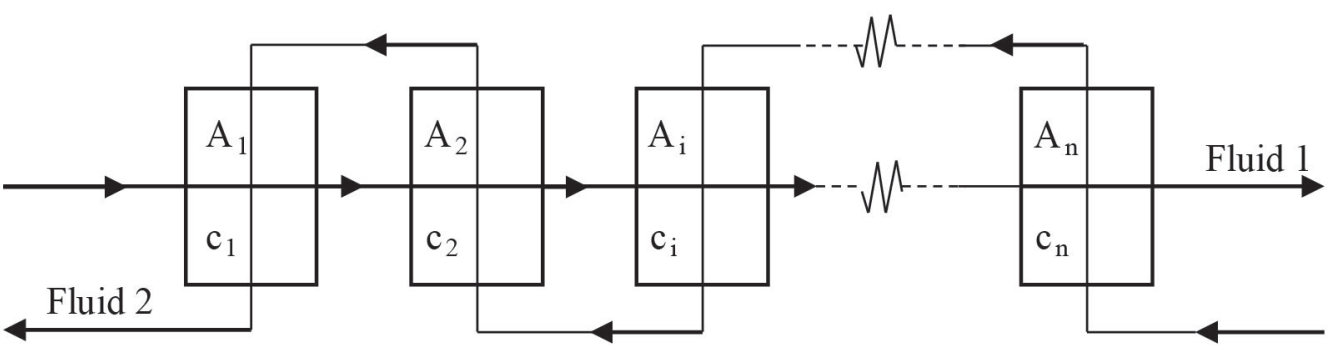

Figure 1. Heat exchanger combination in series with countercurrent flow of fluids.

In case of the countercurrent flows of the fluid streams with heat exchanger arrangement in series connection, Shah and Sekulić (Rohsenow et al., 1985) presented a method for calculating overall heat exchanger effectiveness, $\varepsilon^{*}$, when each heat exchanger has the same heat exchanger effectiveness, $\varepsilon$, as

$$
\varepsilon^{*}=\frac{[(1-\varepsilon c) /(1-\varepsilon)]^{\mathrm{n}}-1}{[(1-\varepsilon c) /(1-\varepsilon)]^{\mathrm{n}}-\mathrm{c}} .
$$

Therefore, the outlet temperature of the working fluid could be calculated by

$$
\mathrm{T}_{\mathrm{fo}}=\frac{\varepsilon^{*} \cdot\left(\mathrm{mi}_{\mathrm{p}}\right)_{\min } \cdot\left(\mathrm{T}_{\mathrm{gi}}-\mathrm{T}_{\mathrm{fi}}\right)}{\left(\mathrm{mi}_{\mathrm{p}}\right)_{\mathrm{f}}}+\mathrm{T}_{\mathrm{fi}}
$$

In this study, the effectiveness curves of heat exchanger were created with the values of heat capacity ratio, $c=\frac{\left(m c_{p}\right)_{\min }}{\left(m c_{p}\right)_{\max }}=\frac{\left(m c_{p}\right)_{g}}{\left(m c_{p}\right)_{f}}$, and number of transfer unit of helical coil, $\mathrm{NTU}_{\text {min }}^{*}=\mathrm{n} . \mathrm{NTU}_{\text {min }}$, where $\mathrm{n}$ is the coil number and $\mathrm{NTU}_{\min }=(\mathrm{UA})_{\mathrm{s}} /\left(\dot{\mathrm{mc}} \mathrm{c}_{\mathrm{p}}\right)_{\min }$. To get the $\mathrm{c}$ values, the hot gas velocity was fixed at $0.66 \mathrm{~m} / \mathrm{s}$ therefore the hot gas mass flow rate was 
fixed. With a stack diameter of $0.3 \mathrm{~m}$, the measured gas average temperature and the gas properties which were assumed to be the same as those of air, the $\left(\dot{m}_{\mathrm{p}}\right)_{\mathrm{g}}$ could be evaluated. By varying the mass flow rate of the working fluid and the measured average fluid temperature, the $\left(\dot{\mathrm{mc}} \mathrm{p}_{\mathrm{p}}\right)_{\mathrm{f}}$ could be also calculated.

\section{Experimental set-up}

Four copper helical coils of which the descriptions were shown in Figure 2 and the details were listed in Table 1, were experimentally investigated for heat transfer characteristics with different heat transfer fluids (DI-water and DI-water based graphene nanofluid). Each coil was installed inside a combustion stack of $0.3 \mathrm{~m}$ in diameter. The hot combustion gas generated by LPG gas burner, shown in Figure 3, flowed through the helical coil with the average gas velocity of $0.66 \mathrm{~m} / \mathrm{s}$. A set of nine calibrated Type-K thermocouples was installed to measure temperatures at three cross-sectional levels (Figure 3), bottom, middle, and top of the helical coil. At each section level of the helical coil, three thermocouples were installed for measuring the hot gas temperature inside the stack $\left(\mathrm{T}_{\mathrm{o}}\right)$, the coil surface temperature $\left(\mathrm{T}_{\mathrm{s}}\right)$ and the water temperature inside the coil $\left(\mathrm{T}_{\mathrm{i}}\right)$. The stack was well insulated.

Table 1. Description of experimental coils.

\begin{tabular}{cccccccc}
\hline Items & \multicolumn{7}{c}{ Dimensions } \\
\hline Coil & $\begin{array}{c}\mathbf{d}_{\mathbf{i}} \\
(\mathbf{m})\end{array}$ & $\begin{array}{c}\mathbf{d}_{\mathbf{o}} \\
(\mathbf{m})\end{array}$ & $\begin{array}{c}\mathbf{D} \\
(\mathbf{m})\end{array}$ & $\mathbf{p} / \mathbf{d i}$ & $\mathbf{N}$ & $\mathbf{L}$ & $\mathbf{H}$ \\
& 0.015 & 0.016 & 0.245 & 2 & 14 & 11.67 & 0.65 \\
\hline 1 & 0.012 & 0.013 & 0.245 & 2.5 & 14 & 10.5 & 0.68 \\
2 & 0.012 & 0.013 & 0.245 & 4 & 14 & 11.02 & 0.82 \\
3 & 0.012 & 0.013 & 0.19 & 4 & 14 & 9.38 & 0.82 \\
4 & & & & & & & \\
\hline
\end{tabular}



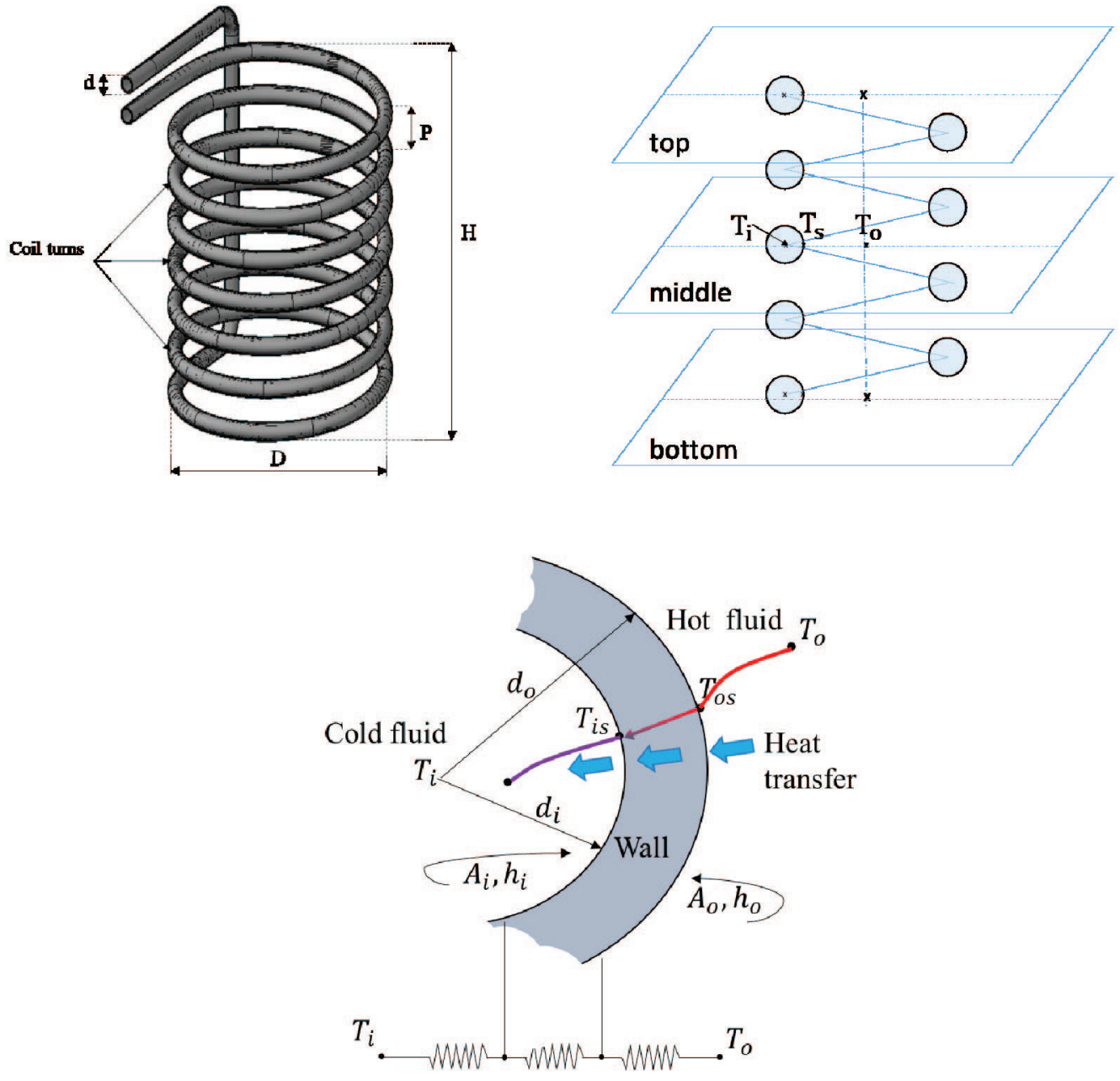

Figure 2. Helical coil schematic sketch and heat transfer direction.

The hot gas temperature was controlled to be around $200^{\circ} \mathrm{C}$ and the gas velocity flowing inside the stack was $0.66 \mathrm{~m} / \mathrm{s}$ (the air properties were taken for the hot gas calculation). The volume flow rates of the working fluids both DI-water and DI-water/GNPs were varied in a range of $0.25-2 \mathrm{~L} / \mathrm{min}$ corresponding to the Reynolds number $\left(\operatorname{Re}_{\mathrm{i}}=\frac{\rho \mathrm{vd}}{\mu}\right)$ of $500-7,000$. The inlet temperatures of the working fluids were varied in a range of $30-50^{\circ} \mathrm{C}$. The accuracies of the experimental instruments were described in Table 2. 


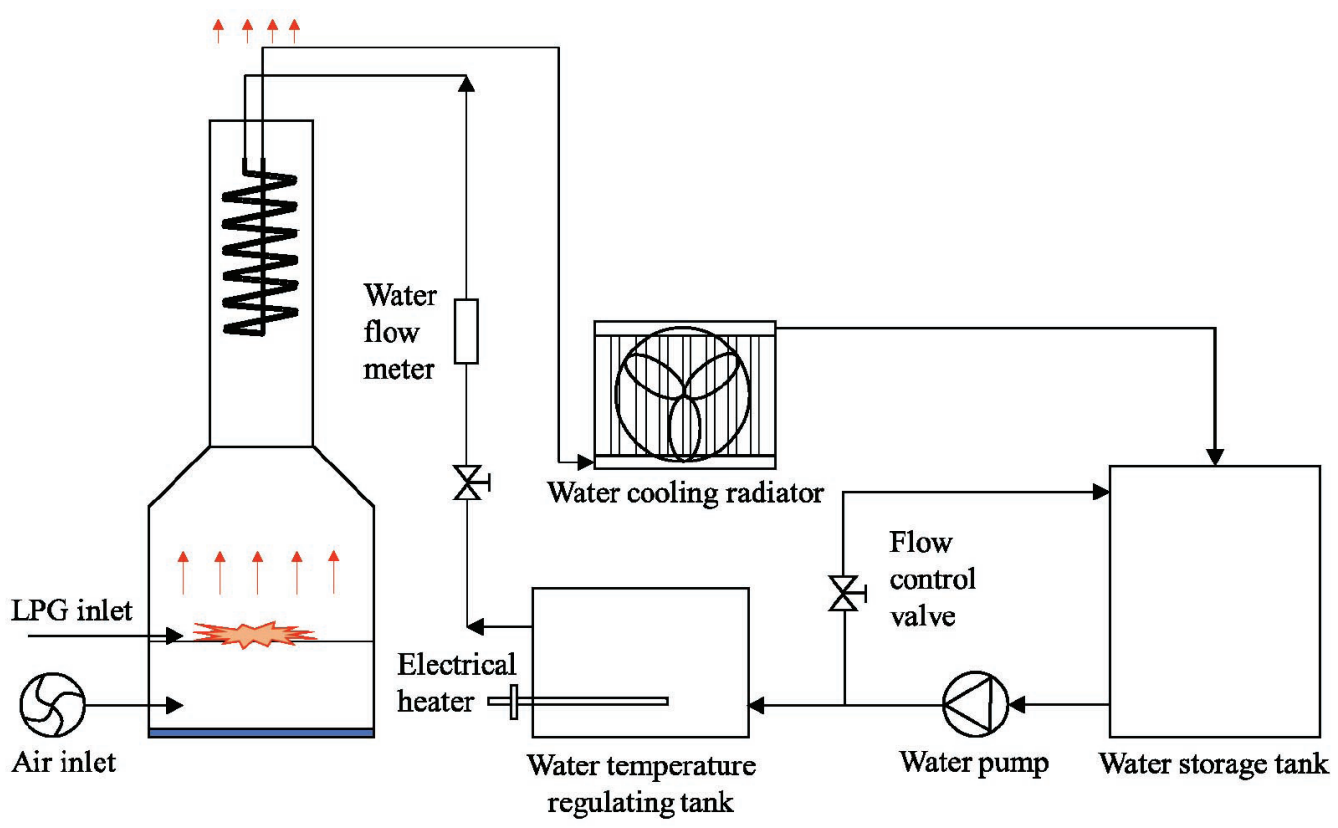

Figure 3. Experimental setup.

Table 2. Accuracies of the experimental measuring instruments.

\begin{tabular}{|c|c|c|}
\hline Tools & Characteristics & Accuracy \\
\hline $\begin{array}{l}\text { Data-logger } \\
\text { S220-T8 }\end{array}$ & $\begin{array}{l}\text { Measuring the temperatures of fluids, coil surface, } \\
\text { and ambient temperature. }\end{array}$ & $\pm 0.05^{\circ} \mathrm{C}$ \\
\hline $\begin{array}{l}\text { Thermocouple } \\
\text { type K }\end{array}$ & Range: -200 to $350{ }^{\circ} \mathrm{C}$ & $\pm 0.5^{\circ} \mathrm{C}$ \\
\hline Flow meter & $\begin{array}{l}\text { Measure water flow rate } \\
\text { Range: } 0-21 / \mathrm{min}\end{array}$ & $\pm 1 \%$ \\
\hline Water pump & $\begin{array}{l}\text { QPM60 pompa, SUMOTO } \\
\text { Measuring water flow rate } \\
\text { Range: } 5-401 / \mathrm{min}\end{array}$ & $\pm 2 \%$ \\
\hline Air blower & $\begin{array}{l}\text { Model: SB-30 } \\
\text { Blowing air into system to generate hot gas } \\
\text { Range: } 1-7 \mathrm{~m}^{3} / \mathrm{min}\end{array}$ & $\pm 5 \%$ \\
\hline
\end{tabular}

The uncertainties of heat transfer rate $\delta \dot{\mathrm{Q}}_{\text {uncert }}$ and overall convective heat transfer coefficient $\delta \mathrm{U}_{\text {s,uncert }}$ could be found from uncertainty standard equation as

$$
\delta \dot{\mathrm{Q}}_{\text {uncert }}=\sqrt{\left(\frac{\partial \dot{\mathrm{Q}}}{\partial \mathrm{m}} \cdot \delta \dot{\mathrm{m}}\right)^{2}+\left(\frac{\partial \dot{\mathrm{Q}}}{\partial \mathrm{C}_{\mathrm{p}}} \cdot \delta \mathrm{C}_{\mathrm{p}}\right)^{2}+\left(\frac{\partial \dot{\mathrm{Q}}}{\partial \Delta \mathrm{T}} \cdot \delta \Delta \mathrm{T}\right)^{2}} .
$$




$$
\delta \mathrm{U}_{\mathrm{s}, \text { uncert }}=\sqrt{\left(\frac{\partial \mathrm{U}_{\mathrm{s}}}{\partial \dot{\mathrm{Q}}} \cdot \delta \dot{\mathrm{Q}}\right)^{2}+\left(\frac{\partial \mathrm{U}_{\mathrm{s}}}{\partial \mathrm{A}_{\mathrm{s}}} \cdot \delta \mathrm{A}_{\mathrm{s}}\right)^{2}+\left(\frac{\partial \mathrm{U}_{\mathrm{s}}}{\partial \Delta \mathrm{T}_{\mathrm{Lm}}} \cdot \delta \Delta \mathrm{T}_{\mathrm{Lm}}\right)^{2}} .
$$

The results of the uncertainties were calculated and listed in Table 3. The maximum value was around $10 \%$.

Table 3. Uncertainties of some important parameters, heat transfer rate and overall heat transfer coefficient.

\begin{tabular}{cccccccc}
\hline $\begin{array}{c}\boldsymbol{\delta} \mathbf{A}_{\mathbf{s}} \\
\left(\mathbf{m}^{2}\right)\end{array}$ & $\begin{array}{c}\boldsymbol{\delta} \boldsymbol{\rho} \\
\left(\mathbf{k g} / \mathbf{m}^{\mathbf{3}}\right)\end{array}$ & $\begin{array}{c}\boldsymbol{\delta} \mathbf{C}_{\mathbf{p}} \\
(\mathbf{J} / \mathbf{k g} . \mathbf{k})\end{array}$ & $\begin{array}{c}\boldsymbol{\delta} \dot{\mathbf{V}} \\
\left(\mathbf{m}^{3} / \mathbf{s}\right)\end{array}$ & $\begin{array}{c}\boldsymbol{\delta} \mathbf{T} \\
\left({ }^{\circ} \mathbf{C}\right)\end{array}$ & $\begin{array}{c}\boldsymbol{\delta} \Delta \mathbf{T}_{\mathbf{L m}} \\
\left({ }^{\circ} \mathbf{C}\right)\end{array}$ & $\begin{array}{c}\boldsymbol{\delta} \dot{\mathbf{Q}} \\
(\mathbf{W})\end{array}$ & $\begin{array}{c}\boldsymbol{\delta} \mathbf{U}_{\mathbf{s}} \\
\left(\mathbf{W} / \mathbf{m}^{2} \cdot \mathbf{K}\right)\end{array}$ \\
\hline 0.017 & 5 & 1 & $1.67 \mathrm{e}-7$ & 0.7 & 1.06 & 88.17 & 1.59 \\
$(3.8 \%)$ & $(0.51 \%)$ & $(0.02 \%)$ & $(1 \%)$ & $(1.5 \%)$ & $(0.8 \%)$ & $(10.8)$ & $(9.9 \%)$ \\
\hline
\end{tabular}

\section{Nanofluid preparation}

In this study, the DI-water and DI-water based graphene nanofluid at graphene particle fractions of 0.05 and $0.08 \%$ by weight were selected for the working fluids inside the helical coils. The specifications of graphene nanoplatelets with particle fraction of 0.05 and 0.08 wt.\% were listed in Table 4. The particles were mixed with DI-water by $40 \mathrm{kHz}$ ultrasonic generator for 30 minutes. The thermal and the rheological properties of the working fluid were determined at the average fluid bulk temperature between the coil inlet and coil outlet temperatures of the working fluid. The details of the properties and the stability of the nanofluid were described in the M.Eng. dissertation of Kong et al., (2018) and some of the results were shown in Figure 4.

Table 4. Specification of graphene nanoplatelets.

\begin{tabular}{ll}
\hline Property & Description \\
\hline Particle & GNPs \\
Type & Black powder \\
Carbon content & $>99.5 \%$ \\
Density & $2,250 \mathrm{~kg} / \mathrm{m}^{3}$ \\
Particle diameter & $2 \mu \mathrm{m}$ \\
Specific surface area & $500 \mathrm{~m}^{2} / \mathrm{g}$ \\
Thickness & $2 \mathrm{~nm}$ \\
Thermal conductivity & $3,000 \mathrm{~W} / \mathrm{m} . \mathrm{K}$ (Parallel to surface) \\
& $6 \mathrm{~W} / \mathrm{m} . \mathrm{K}$ (Perpendicular to surface) \\
\hline Specific heat & $700 \mathrm{~J} / \mathrm{kg} \cdot \mathrm{K}$ \\
\hline
\end{tabular}



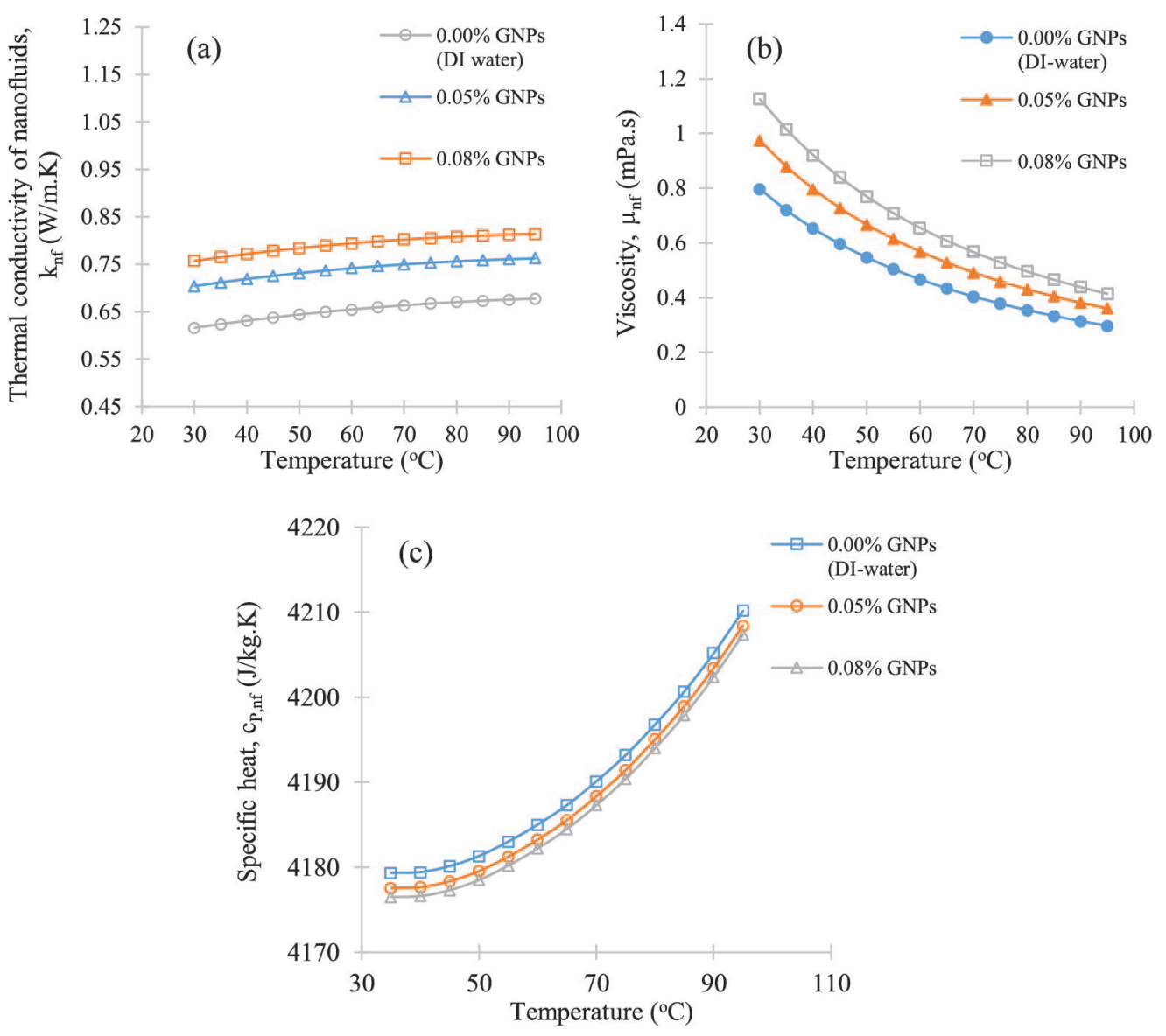

Figure 4. Thermal properties of DI-water/GNPs nanofluids at various temperatures: (a) thermal conductivity, (b) viscosity, and (c) specific heat. (Kong et al., 2018).

\section{RESULTS}

\section{Heat transfer rate by DI-water and nanofluids}

Based on the temperature difference between the coil inlet and outlet temperatures of the working fluids, the heat transfer rates extracted by the working fluids from the hot gas were evaluated using equation (2) and shown in Figure 5.

The results showed that the heat rates increased with the increase of Reynolds number or the flow rate of the working fluids. The inside coil Reynolds number was calculated using fluid properties determined at average fluid bulk temperature between the coil inlet and coil outlet temperatures of the working fluid. The presence of the particles in the base fluid increased significantly the heat transfer rate due to the higher thermal conductivity of the nanofluid. 


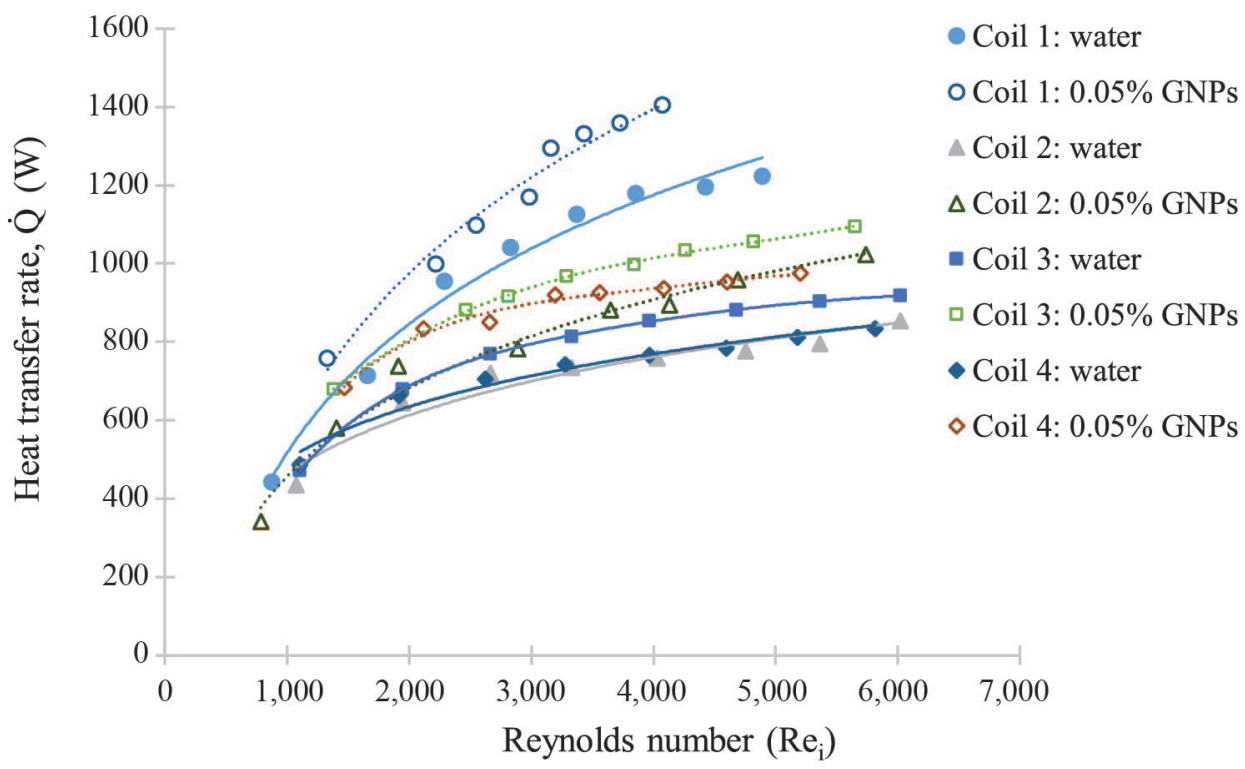

Figure 5. Heat transfer rates extracted by DI-water and graphene nanofluids at particle fraction of $0.05 \mathrm{wt} . \%$ with different helical coils.

\section{Overall heat transfer coefficient of helical coils}

The overall heat transfer coefficients of the helical coiled heat exchanger could be determined from the heat transfer rate extracted by the working fluids shown in Figure 5 and the log-mean temperature difference between the fluid streams using equation (2). The results of the overall heat transfer coefficients of all helical coils with DI-water and nanofluid at particle fraction of $0.05 \mathrm{wt} . \%$ were shown in Figure 6 . The results showed that the overall heat transfer coefficient increased with the increase of inside Reynolds number or flow rate of the working fluids. 


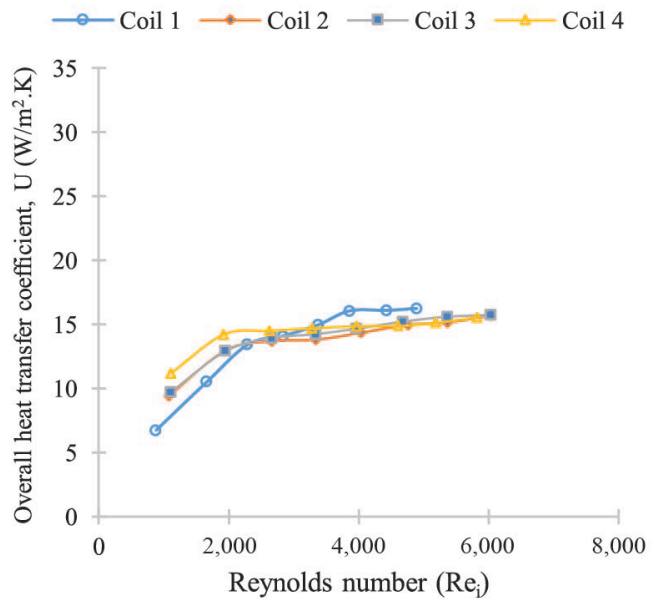

(a) DI-water

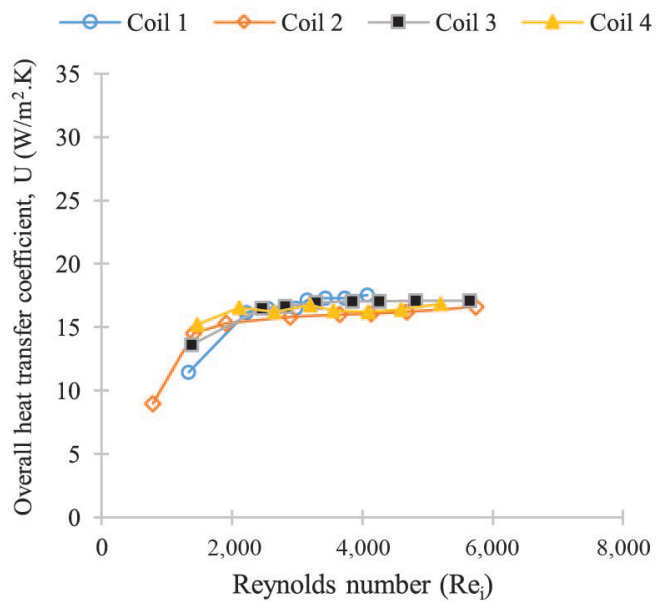

(b) Nanofluid at $0.05 \mathrm{wt} . \%$

Figure 6. Overall heat transfer coefficient of the helical coils with DI-water and nanofluid at 0.05 wt. \% particle fraction.

However, when the Reynolds number was over around 2,000, the overall heat transfer coefficient increased slightly, which meant that the gas-side convective heat transfer coefficient controlled the overall heat transfer coefficient of the heat exchangers. The overall heat transfer coefficients with nanofluid showed better trends compared to those with DI-water.

\section{Heat exchanger effectiveness of heat recovery from combustion stack gas}

The experimental results on heat exchanger effectiveness for single unit of all coils were determined using equation (1) for both working fluids, DI-water and nanofluids at particle concentration of $0.05 \mathrm{wt} . \%$. With these results, the total effectiveness of the helical coils connected in series was performed using equation (4). The overall performance curves of the heat exchangers in series connection in terms of heat capacity ratio (c) and number of transfer unit $\left(\mathrm{NTU}_{\text {min }}^{*}\right)$ were also created as shown in Figure 7. 
Performance of helical coil 1

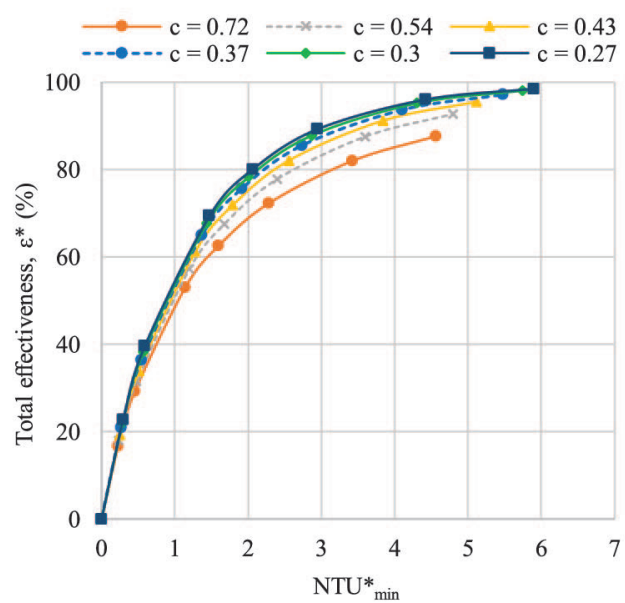

Performance of helical coil 3

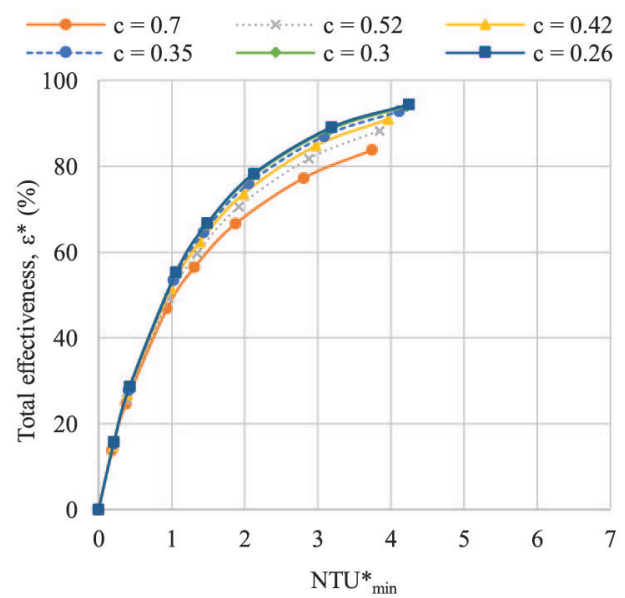

Performance of helical coil 2

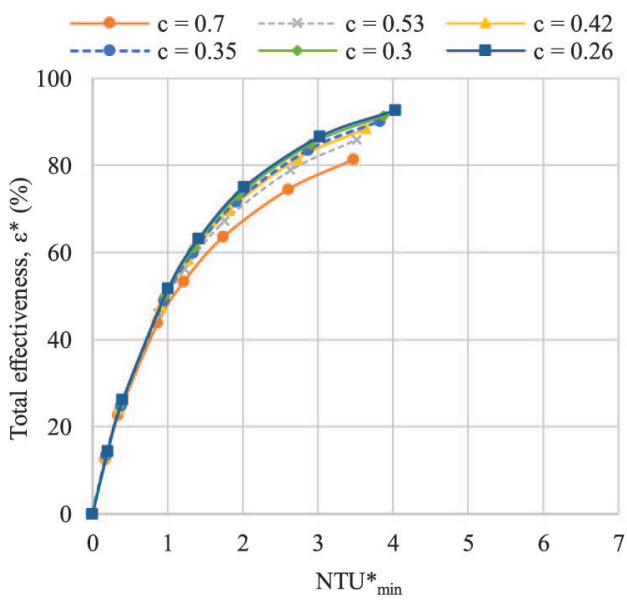

Performance of helical coil 4

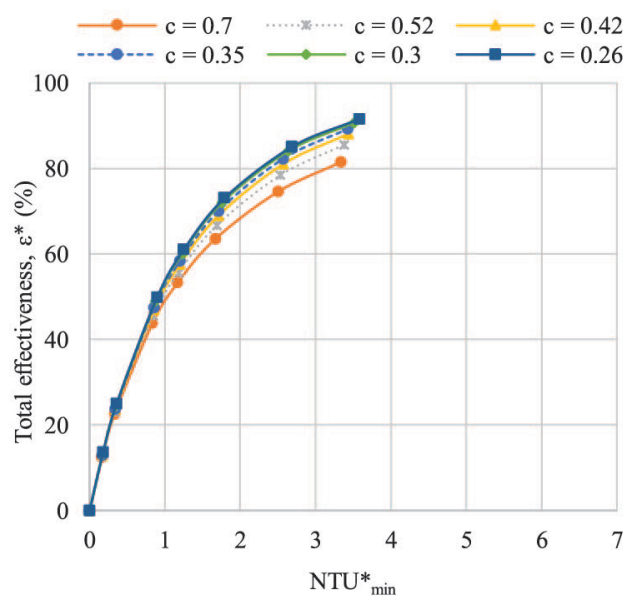

(a) DI-water.

Figure 7. Total effectiveness of helical coils in series connection against total number of transfer unit. (a) with DI-water and (b) with nanofluid at 0.05 wt.\% particle fraction. 
Performance of helical coil 1

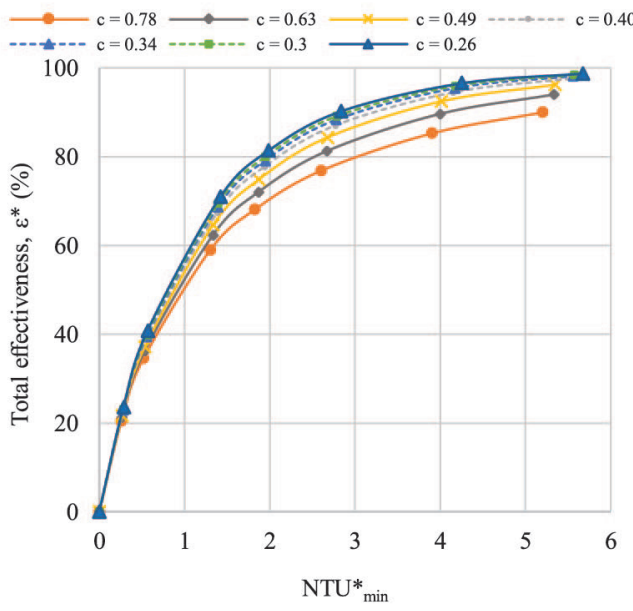

Performance of helical coil 3

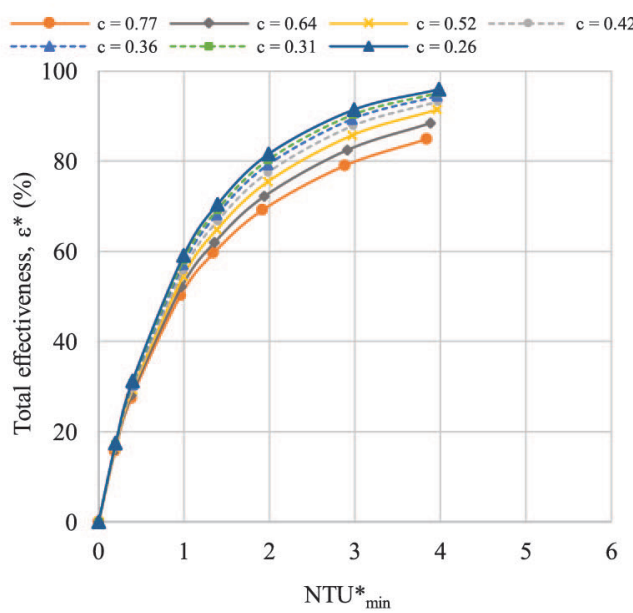

Performance of helical coil 2

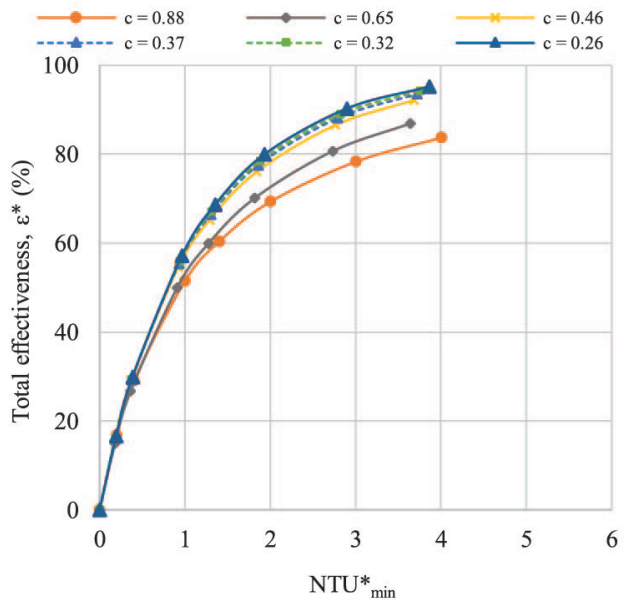

Performance of helical coil 4

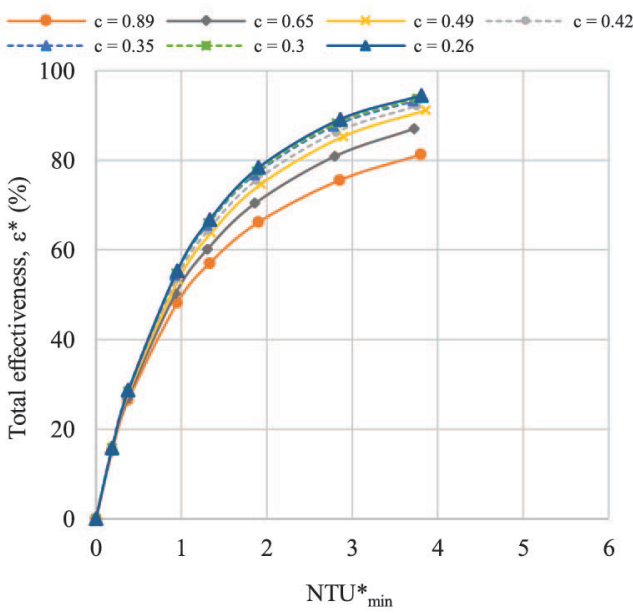

(b) Nanofluid at 0.05 wt.\%.

Figure 7. Continued.

\section{Outlet temperature of working fluids with number of the helical coils}

Coil 1 was selected to consider the outlet water temperature of the working fluids, DIwater and nanofluid at particle fraction of $0.05 \mathrm{wt} . \%$, due to its better heat transfer performance (Figure 7) compared to other coils (coil 2-4). The working fluid outlet temperatures were simulated with the number of helical coils connected in series using equation (5). The simulated outlet temperature profiles with various flow rates of working fluids were shown in Figure 8. The fluid inlet temperatures were fixed at $30^{\circ} \mathrm{C}$. 


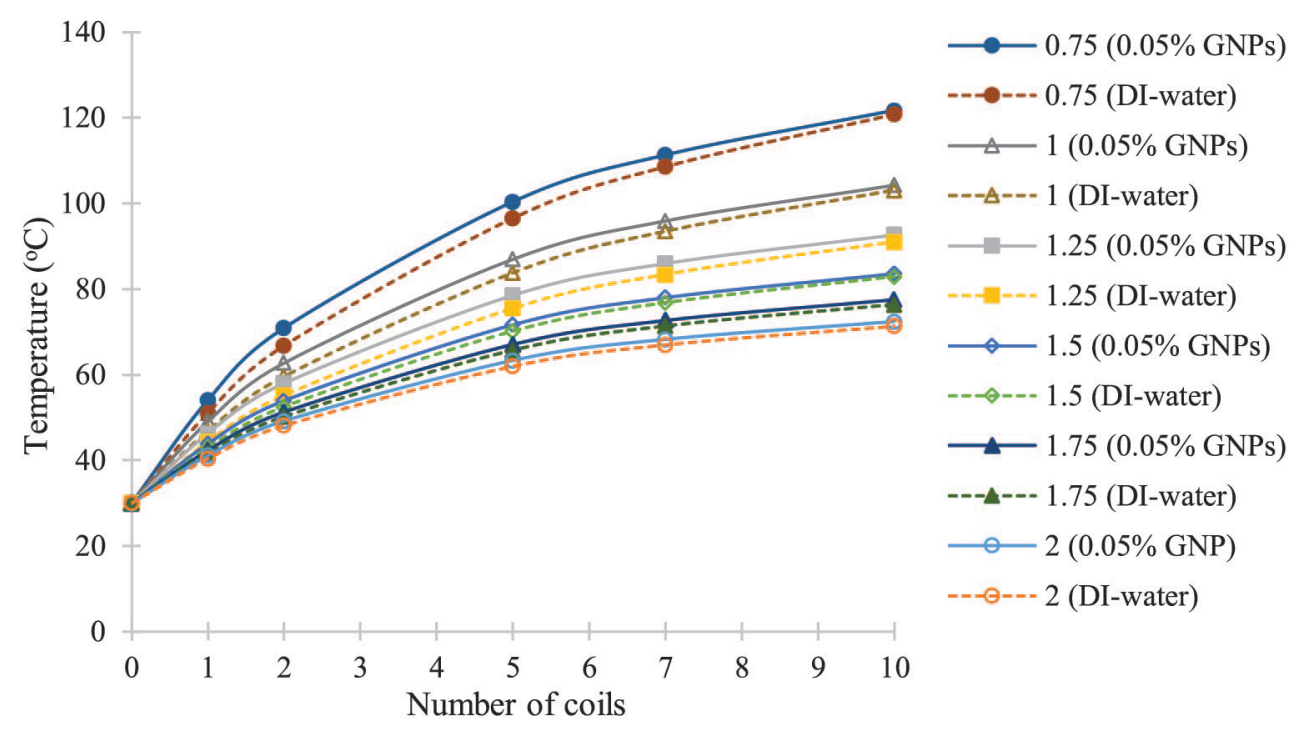

Figure 8. Calculated outlet temperatures of the DI-water and the nanofluid at various flow rates (the values $0.75-2$ were in $\mathrm{L} / \mathrm{min}$ ) with the helical coil number (coil 1).

\section{DISCUSSION}

From Figure 4, the thermal conductivities of the nanofluids increased around 13.4 and $21.4 \%$ and the specific heat capacities decreased around 0.04 and $0.07 \%$ for particle concentrations of 0.05 and $0.08 \mathrm{wt} . \%$, respectively. Therefore, the nanofluid could enhance the heat transfer coefficient and the higher working fluid outlet temperature could be achieved. However, the increase of particle concentration was limited since higher particle concentration in base fluid could generate greater viscosity. Around 21.8 and $40.4 \%$ increases of nanofluid viscosity were found for 0.05 and $0.08 \mathrm{wt} . \%$ GNPs, respectively, compared to that of pure DIwater. High viscosity could reduce the stability of the nanofluids and generate more friction and higher pressure drop of the fluid flow inside the tube Mehrali et al., (2014). It should be recommended that the concentration of the nanoparticles should be less than $0.1 \mathrm{wt} . \%$.

From Figure 5, it could be noted that coil 1 (surface area of $0.54 \mathrm{~m}^{2}$ ) gave the best performance due to its highest heat transfer surface area followed by coil 3 (surface area of 0.4 $\mathrm{m}^{2}$ ) and coil $2\left(\right.$ surface area of $0.38 \mathrm{~m}^{2}$ ). For coil 4, even the surface area was smallest (surface area of $0.34 \mathrm{~m}^{2}$ ), but the obtained heat transfer rate was close to coil 3 and higher than coil 2 because coil 4 was installed around the center of the stack where the gas flow velocity was nearly maximum. In addition, the coil diameter was smaller, then the liquid side heat transfer coefficient was more turbulent, therefore, the overall heat transfer coefficient was higher as the results shown in Figure 6. 
In Figure 5, the nanofluids also showed better heat transfer performance for all coils compared with DI-water. The heat transfer rates extracted by the nanofluids at particle fraction of $0.05 \mathrm{wt} . \%$ or $0.02 \%$ in volume fraction increased around $13.1 \%$ for coil $1,16.8 \%$ for coil 2 , $17.6 \%$ for coil 3 , and $18.2 \%$ for coil 4 since the heat transfer coefficient of the working fluid increased around $23.2 \%, 21.4 \%, 24 \%$, and $25 \%$ for coils $1,2,3$ and 4 , respectively, compared to the results of DI-water. These results possessed better heat transfer performance compared to that of the ethylene glycol-DI-water/ $\mathrm{TiO}_{2}\left(0.02 \% \mathrm{TiO}_{2}\right)($ Chandra and Vasudeva., 2014) and water/PANI (polyaniline) (0.1\% PANI) (Bhanvase et al., 2018) nanofluids that could increase heat transfer coefficient around $13.8 \%$ and $10.5 \%$, respectively, due to high thermal conductivity of GNPs.

Figure 6 showed overall heat transfer coefficient of the helical coils with DI-water and nanofluid at $0.05 \mathrm{wt} . \%$ particle fraction. It could be found that the overall heat transfer coefficients were enhanced for the units with nanofluids. When the liquid-side Reynolds number was over 2,000, the values could be increased from 14-16 for DI-water to around16-18 $\mathrm{W} / \mathrm{m}^{2} . \mathrm{K}$ for the nanofluids. When the liquid-side Reynolds number was less than 2,000 , the values from 6-14 were up to $8-16 \mathrm{~W} / \mathrm{m}^{2} . \mathrm{K}$, respectively.

The heat exchanger effectiveness with the $\mathrm{NTU}^{*}{ }_{\text {min }}$ of the coils in series connection is presented in Figure 7. It could be found that the effectiveness curves of the nanofluid were slightly higher than those of DI-water at a given value of $\mathrm{NTU}^{*}{ }_{\text {min }}$, which meant that the nanofluid enhanced the heat exchanger performance. The outlet temperatures of the nanofluid were found to be higher than those of the DI-water and these were confirmed by the results in Figure 8.

With a good trend of higher performance curves, helical coil 1 was selected for coil outlet temperature of the working fluid. For 5 units of coils 1 in series connection, with the working fluid flow rates of 0.75 and $2 \mathrm{~L} / \mathrm{min}$, the outlet temperatures of the nanofluid containing graphene nanoparticles at $0.05 \mathrm{wt} . \%$ were 2.5 and $1.3^{\circ} \mathrm{C}$ over than those of the DIwater, respectively. In addition, when the unit number was over 7, the outlet temperatures of the working fluids slightly increased, particularly for high fluid flow rates.

From the study, it could be noted that the GNPs with suitable particle concentrations could enhance very well the working fluid heat transfer performance and also the heat exchanger effectiveness. For helical coils, the unit with bigger tube diameter should be selected to get higher heat transfer surface area and the coil installation should be close to the center of the stack.

The stability of the nanofluid flowing in the coiled tube is also another main aspect. The particle deposition on the heat transfer surface and the long-term performance of the nanofluid should be studied in more details. 


\section{CONCLUSION}

In this research paper, the waste heat recovery from combustion stack gas was carried out by helical coiled heat exchangers having DI-water and nanofluid as working fluids in fully developed laminar flows. The results on the thermal characteristics of the heat recovery could be noted as

- The nanoparticles could enhance very well the thermal performance of the base fluid (DI-water). The nanofluid had higher thermal conductivity and lower specific heat capacities, which resulted in better heat transfer coefficient and higher working fluid outlet temperature compared to those from pure DI-water.

- The $\varepsilon^{*}-\mathrm{NTU}^{*}{ }_{\text {min }}$ performance curves of helical coils in series connection were created from Shah and Sekulić model. The heat exchanger performances were increased with the increase of coil number. The nanofluid also gave better heat exchanger performance than the base fluid (DI-water).

- The outlet temperature of the nanofluid was found to be higher than that of the base fluid. For coil 1, with 5 coil numbers and the flow rate of $2 \mathrm{~L} / \mathrm{min}$, the outlet temperature of the nanofluid was $1.3^{\circ} \mathrm{C}$ over than that of the DI-water. When the coil number was over 7 , the nanofluid gave advantage on the outlet temperature compared with the base fluid only slightly.

\section{ACKNOWLEDGEMENT}

The authors are thankful to Graduate School, Department of Mechanical Engineering, Faculty of Engineering, and Center of Excellence for Renewable Energy, Chiang Mai University for supporting testing facilities and some expenses. The authors would like to acknowledge the National Research Council of Thailand (the Sino-Thai Project) for the financial support.

\section{Nomenclature:}

$\Delta \mathrm{T}_{\mathrm{Lm}}$ log-mean temperature difference (LMTD) $[\mathrm{K}]$

$\mathrm{d} \quad$ coiled tube diameter $[\mathrm{m}]$

$\mathrm{p} \quad$ coil pitch $[\mathrm{m}]$

D coil diameter $[\mathrm{m}]$

$\mathrm{N}$ number of coil turns

L coil length $[\mathrm{m}]$

$\mathrm{H} \quad$ coil height $[\mathrm{m}]$

Re Reynolds number $\left(\operatorname{Re}=\frac{\rho v d}{\mu}\right)$

NTU number of transfer of a single unit of coil, (* for many units in series connection)

$\varepsilon \quad$ effectiveness of a single unit of coil [\%], (* for many units in series connection)

$\mathrm{n}$ number of coils in series connection

$\mathrm{T}$ temperature $\left[{ }^{\circ} \mathrm{C}\right]$

GNPs graphene nanoplatelets

$\mathrm{c}_{\mathrm{p}} \quad$ specific heat $[\mathrm{J} / \mathrm{kg}$. K]

$\mathrm{c}$ heat capacity ratio [dimensionless] 


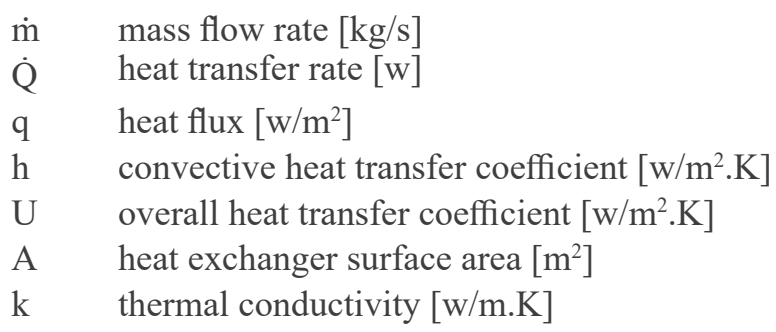

\section{Subscripts:}

i inside or inlet

o outside or outlet

f working fluid side

g hot gas side

nf nanofluid

$\mathrm{s} \quad$ tube wall surface

min minimum

max maximum

\section{REFERENCES}

Ali, M.E. 1994. Experimental investigation of natural convection from vertical helical coiled tubes. International Journal of Heat and Mass Transfer. 37(4): 665-671. https://doi. org/10.1016/0017-9310(94)90138-4

Bhanvase, B.A., Sayankar, S.D., Kapre, A., Fule, P.J., and Sonawane, S.H. 2018. Experimental investigation on intensified convective heat transfer coefficient of water based PANI nanofluid in vertical helical coiled heat exchanger. Applied Thermal Engineering. 128: 134-140. https://doi.org/10.1016/j.applthermaleng.2017.09.009

Chandra Sekhara Reddy, M., and Vasudeva Rao, V. 2014. Experimental investigation of heat transfer coefficient and friction factor of ethylene glycol water based $\mathrm{TiO}_{2}$ nanofluid in double pipe heat exchanger with and without helical coil inserts. International Communications in Heat and Mass Transfer. 50: 68-76. https://doi.org/10.1016/j. icheatmasstransfer.2013.11.002

Dravid, A.N., Smith, K.A., Merrill, E.W., and Brian, P.L.T. 1971. Effect of secondary fluid motion on laminar flow heat transfer in helically coiled tubes. AIChE Journal. 17(5): 1114-1122. https://doi.org/10.1002/aic.690170517

Farajollahi, B., Etemad, S.Gh., and Hojjat, M. 2010. Heat transfer of nanofluids in a shell and tube heat exchanger. International Journal of Heat and Mass Transfer. 53(1): 12-17. https://doi.org/10.1016/j.ijheatmasstransfer.2009.10.019

Fule, P.J., Bhanvase, B.A., and Sonawane, S.H. 2017. Experimental investigation of heat transfer enhancement in helical coil heat exchangers using water based $\mathrm{CuO}$ nanofluid. Advanced Powder Technology. 28(9): 2288-2294. https://doi.org/10.1016/J. APT.2017.06.010 
Janssen, L.A.M., and Hoogendoorn, C.J. 1978. Laminar convective heat transfer in helical coiled tubes. International Journal of Heat and Mass Transfer. 21(9): 1197-1206. https://doi.org/10.1016/0017-9310(78)90138-2

Kahani, M., Zeinali Heris, S., and Mousavi, S.M. 2013. Effects of curvature ratio and coil pitch spacing on heat transfer performance of $\mathrm{Al}_{2} \mathrm{O}_{3}$ /water nanofluid laminar flow through helical coils. Journal of Dispersion Science and Technology. 34(12): 17041712. https://doi.org/10.1080/01932691.2013.764485

Kong, R., Deethayat, T., Asanakham, A., and Kiatsiriroat, T. 2018. Heat transfer phenomena on waste heat recovery of combustion stack gas with deionized water in helical coiled heat exchanger. Case Studies in Thermal Engineering. 12: 213-222. https://doi. org/10.1016/J.CSITE.2018.04.010

Mahian, O., Kianifar, A., Kalogirou, S.A., Pop, I., and Wongwises, S. 2013. A review of the applications of nanofluids in solar energy. International Journal of Heat and Mass Transfer. 57(2): 582-594. https://doi.org/10.1016/j.ijheatmasstransfer.2012.10.037

Mehrali, M., Sadeghinezhad, E., Latibari, S., Kazi, S., Mehrali, M., Zubir, M.N.B.M., and Metselaar, H.S. 2014. Investigation of thermal conductivity and rheological properties of nanofluids containing graphene nanoplatelets. Nanoscale Research Letters. 9(1): 15. https://doi.org/10.1186/1556-276X-9-15

Polvongsri, S., and Kiatsiriroat, T. 2014. Performance analysis of flat-plate solar collector having silver nanofluid as a working fluid. Heat Transfer Engineering. 35(13): 1183-1191. https://doi.org/10.1080/01457632.2013.870003

Rohsenow, W.M., Hartnett, J.P., and Ganić, E.N. 1985. Handbook of Heat Transfer Applications. McGraw-Hill, New York.

Schmidt, E.F. 1967. Heat transfer and pressure loss in spiral tubes. Chemie Ingenieur Technik. 39(13): 781-789.

Tayde, M., Wankhade, J., and Channapattana, S. 2014. Heat transfer analysis of a helically coiled heat exchanger. International Journal of Innovative Research and Developmen. 3 (13): 265-268.

Xin, R.C., and Ebadian, M.A. 1997. The effects of prandtl numbers on local and average convective heat transfer characteristics in helical pipes. Journal of Heat Transfer. 119(3): 467-473. https://doi.org/10.1115/1.2824120

Zhou, N., Wang, X., Chen, Z., and Wang, Z. 2013. Experimental study on organic rankine cycle for waste heat recovery from low-temperature flue gas. Energy. 55: 216-225. https://doi.org/10.1016/j.energy.2013.03.047 